\title{
Beta-Lactamases Production in Multi-drug Resistant Acinetobacter species Isolated from Different Clinical Specimens
}

\author{
Mary Neupane ${ }^{1}$, Sudeep K. C. ${ }^{1}$, Subash Kumar Thakur ${ }^{2}$, Om Prakash Panta ${ }^{1}$, Dev Raj Joshi ${ }^{3}$, \\ Santosh Khanal ${ }^{*}$ \\ ${ }^{1}$ Department of Microbiology, National College, Khusibu, Kathmandu, Nepal \\ 2Department of Pathology, Paropakar Maternity and Women's Hospital, Kathmandu, Nepal \\ ${ }^{3}$ Central Department of Microbiology, Tribhuvan University, Kirtipur, Kathmandu, Nepal
}

*Corresponding author: Santosh Khanal, Department of Microbiology, National College, Khusibu, Kathmandu; E-mail: santoshkhanal007@gmail.com

\begin{abstract}
Objectives: To determine the prevalence of Acinetobacter spp. from different clinical specimens and detect different types of $\beta$-lactamase enzymes.

Methods: Different clinical samples were collected and 125 Acinetobacter spp. were isolated. Various biochemical tests were carried out to speciate the Acinetobacter spp. The antibiotic susceptibility pattern and $\beta$-lactamase enzymes like Extended spectrum $\beta$-lactamase (ESBL), Metallo $\beta$-lactamase (MBL) and AmpC $\beta$-lactamase were determined.
\end{abstract}

Results: Of the total 125 isolates, the most predominant species was Acinetobacter calcoaceticus-A. baumannii (Acb) complex (80\%). Highest rate of isolation of Acinetobacter species were from in-patients (neonates' blood sample). Among all, 44.8\% isolates were found to be MDR with the majority being resistant to aminoglycosides, carbapenems and fluoroquinolones but not to colistin. ESBL, MBL and AmpC beta-lactamase was detected in $43.2 \%, 15.2 \%$ and $1.6 \%$ of the isolates respectively.

Conclusion: Acinetobacter calcoaceticus-A. baumannii complex should be considered for detection in hospitalized patients. The analysis of antibiotic susceptibility pattern and $\beta$-lactamases would be helpful to establish network surveillance in order to maintain and control the spread of these resistant strains.

Key words: Acinetobacter species, Acb complex, ESBL, MBL, AmpC beta-lactamase.

\section{INTRODUCTION}

Gram-negative bacteria cause different infections, which are becoming increasingly prevalent and constitute a serious threat to public health worldwide. Systemic infections from these organisms are difficult to treat and carry unacceptably high mortality, as high as $50 \%$ because of lack of efficacious treatment regimens (Kaye and Pogue 2015).

Genus Acinetobacter comprises more than 50 validly named species. The most significant among them is A. baumannii (Kolk et al. 2019) that commonly infects immuno-compromised patients (Park et al. 2017). They are ubiquitous organisms and prevail in natural environments (Kolk et al. 2019). They also represent the normal flora in humans (Almasaudi 2016).
Acinetobacter have emerged as one of the most troublesome classes of pathogen in health careassociated infections (Silveira et al. 2019). They cause various infections like hospital-acquired pneumonia, community-acquired pneumonia, bacteremia, trauma and wound infection, urinary tract infection, meningitis and other manifestations like endocarditis, peritonitis, opthalmitis or keratitis associated with contact lens use following eye surgery (Almasaudi 2016).

Acinetobacter species are well suited for genetic exchange and have the remarkable capacity for acquisition of foreign genetic material, which helps in obtaining resistance to the antibiotics (Kolk et al. 2019). AbaR1 resistance cluster, which is an $86-\mathrm{kb}$ region, have been identified in Acinetobacter spp. that contains 45

Date of Acceptance: November 28, 2019

DOI: https:/ / doi.org/10.3126/tujm.v6i0.26583

Date of Submission: September 27,
Published Online: December, 2019 
resistance genes in MDR isolates (Perez et al. 2007).

Bacterial resistance against $\beta$-lactam antibiotics is now becoming threat in the interventions of antibiotics due to the production of $\beta$-lactamase enzymes. Khanal et al. (2013) reported the prevalence of ESBL, MBL and AmpC $\beta$-lactamase producing Acinetobacter to be $9.09 \%, 10.90 \%$ and $46.80 \%$ respectively. In another study conducted by Bhandari et al. (2015), 12.5\% ESBL, 63.8\% MBL and $31.37 \%$ AmpC $\beta$-lactamase producing Acinetobacter were reported. OXA-51 of A. baumannii is involved in cephalosporin resistance (AmpC) (Gordon and Wareham 2009).

The spread of multi drug resistant Acinetobacter infection has been increasing and is creating a problem in the treatment. The early detection of MDR isolates and their ability to produce $\beta$-lactamase enzyme is necessary to neutralize the serious threat. So this study was conducted with the objective to identify different Acinetobacter species and to detect various types of $\beta$-lactamases (ESBL, MBL and AmpC $\beta$-lactamase) produced by it that could be helpful for the treatment and analysis of resistance mechanism of this bacterium and to search the alternative therapeutic options.

\section{MATERIALS AND METHODS}

\section{Sample size and study population}

The study was conducted in Paropakar Maternity and Women's Hospital, Kathmandu, Nepal over a period of six months from May to November 2018. Acinetobacter spp. were isolated from various clinical specimens received in Microbiology laboratory of the hospital. A total of 10,265 samples were investigated which included blood sample, ear swab, Eustachian tube, high vaginal swab (HVS), pus and urine. The samples were collected from females and neonates.

\section{Ethical issues}

The informed consent was taken from adult females. In case of neonates, the informed consent was taken from their guardians. Permission to conduct the study was obtained from the participating hospital.

\section{Isolation and identification of Acinetobacter species}

The specimens were directly inoculated on Blood agar and MacConkey agar plates and incubated at $37^{\circ} \mathrm{C}$ for 24 hours. The species of Acinetobacter was identified phenotypically in the laboratory by series of biochemical tests (Table 1) (Gupta et al. 2015).

Table 1: Phenotypic characteristics of Acinetobacter spp.

\begin{tabular}{|c|c|c|c|c|c|}
\hline \multirow[b]{2}{*}{ Name of test } & \multicolumn{5}{|c|}{ Acinetobacter species } \\
\hline & $\begin{array}{c}\text { Acb. } \\
\text { complex }\end{array}$ & $\begin{array}{c}\text { A. } \\
\text { Iwoffii }\end{array}$ & $\begin{array}{c}\text { A. } \\
\text { Haemolyticus }\end{array}$ & A. junnii & $\begin{array}{l}A . \\
\text { radioresistens }\end{array}$ \\
\hline Gram staining & \multicolumn{5}{|c|}{ Gram negative cocci or coccobacilli } \\
\hline Catalase & + & + & + & + & + \\
\hline Oxidase & - & - & - & - & - \\
\hline Motility & - & - & - & - & - \\
\hline Urease & $\mathrm{V}$ & $\mathrm{V}$ & - & - & - \\
\hline Citrate & + & - & + & + & - \\
\hline OF glucose & + & - & V & - & - \\
\hline Nitrate reduction test & - & - & - & - & - \\
\hline Hemolysis & - & - & + & - & - \\
\hline Gelatin Hydrolysis & - & - & + & - & - \\
\hline Growth at 42 & + & - & - & - & - \\
\hline $\begin{array}{l}\text { Chloramphenicol } \\
\text { sensitivity }\end{array}$ & $\mathrm{R}$ & $\mathrm{S}$ & $\mathrm{R}$ & $\mathrm{R}$ & $\mathrm{R}$ \\
\hline Arginine hydrolysis & + & _- & + & + & + \\
\hline
\end{tabular}

+: Positive, - : Negative, V: Variable, S: Sensitivity, R: Resistant, OF: Oxidative-fermentative.

\section{Antibiotic susceptibility testing}

The antibiotic susceptibility tests were performed on Muller-Hinton agar (MHA) via modified KirbyBauer method of disk diffusion following guidelines of CLSI (2018). In this study the antibiotics used were Amikacin $(30 \mu \mathrm{g})$, Ampicillin $(10 \mu \mathrm{g})$, Azithromycin $(15 \mu \mathrm{g})$, Cefixime $(5 \mu \mathrm{g})$, Cefotaxime $(30 \mu \mathrm{g})$, Cefalexin $(30 \mu \mathrm{g})$, Ciprofloxacin $(5 \mu \mathrm{g})$, Colistin $(10 \mu \mathrm{g})$, Gentmicin $(10 \mu \mathrm{g})$, Meropenem $(10 \mu \mathrm{g})$, Nitrofurantoin $(300 \mu \mathrm{g})$,
Norfloxacin $(10 \mu g)$, Piperacillin $(100 \mu g)$, Piperacillintazobactam $(100 / 10 \mu \mathrm{g})$, Tetracycline $(30 \mu \mathrm{g})$, and Trimethoprim-sulfamethoxazole $(1.25 / 23.75 \mu \mathrm{g})$.

\section{Criterion for multidrug resistance}

The defining criterion for an isolate to be multidrug resistant (MDR) was set as resistance to three or more drugs belonging to different structural classes (Magiorakos et al. 2012). 


\section{Tests for ESBL}

The ESBL production in bacterial isolates was screened by using Cefotaxime disc $(30 \mu \mathrm{g})$ and Ceftazidime disc $(30 \mu \mathrm{g})$. If the zone of inhibition was less than or equal to $25 \mathrm{~mm}$ for Cefotaxime and if it was less than or equal to $22 \mathrm{~mm}$ for Ceftazidime, the isolate was considered as potential ESBL producer on the basis of guidelines of CLSI (2018). The screened isolates were further confirmed by combined disc method. Cefotaxime $(30 \mu \mathrm{g})$, Cefotaxime-clavulanate $(30 / 10 \mu \mathrm{g})$ and Ceftazidime $(30 \mu \mathrm{g})$, Ceftazidimeclavulanate $(30 / 10 \mu \mathrm{g})$ were used for confirmation of ESBL producing strains. After overnight incubation at $37^{\circ} \mathrm{C}$, greater than or equal to $5 \mathrm{~mm}$ increase in a zone of diameter for either Cefotaxime/clavulanate (30/10 $\mu \mathrm{g})$ or Ceftazidime/clavulanate $(30 / 10 \mu \mathrm{g})$ vs the zone diameter of Cefotxime $(30 \mu \mathrm{g})$ or Ceftazidime $(30 \mu \mathrm{g})$ was interpreted as ESBL producer as recommended by CLSI (2018).

\section{Tests for MBL}

The screening test for the MBL production was performed by using Imipenem disc $(10 \mu \mathrm{g})$. If the zone of inhibition was less than or equal to $18 \mathrm{~mm}$ for Imipenem, the isolate was considered as potential MBL producer as stated by CLSI (2018). The screened isolates were further confirmed by combined disc method using Imipenem $(10 \mu \mathrm{g})$ alone and in combination with EDTA. After overnight incubation at $37^{\circ} \mathrm{C}$, if the increase in inhibition zone with Imipenem-EDTA disc was greater than or equal to $7 \mathrm{~mm}$ than the Imipenem $(10 \mu \mathrm{g})$ alone, it was interpreted as MBL producer as stated by Anwar et al. (2016) and Sujatha and Goyal (2017).

\section{Tests for AmpC $\beta$-lactamase}

AmpC-lactamase production was screened by using Cefoxitin $(30 \mu \mathrm{g})$ disc. If the zone of inhibition was less than or equal to $14 \mathrm{~mm}$ for Cefoxitin, the isolate was considered as potential AmpC $\beta$-lactamase producer (Saad et al. 2016). The screened isolates were further confirmed by disc approximation test. Imipenem $(10 \mu \mathrm{g})$, Ceftazidime $(30 \mu \mathrm{g})$, Cefoxitin $(30 \mu \mathrm{g})$ and Amoxicillin-clavulanate $(20 / 10 \mu \mathrm{g})$ were used for the confirmation of AmpC $\beta$-lactamase producing strains. After overnight incubation at $37^{\circ} \mathrm{C}$, the plate was examined for any blunting or flattening of the zone of inhibition between the ceftazidime disc and the imipenem, cefoxitin and amoxicillin-clavulanate discs. The presence of any blunting or flattening of the zone was interpreted as AmpC $\beta$-lactamase producer (Saad et al. 2016).

\section{RESULTS}

Out of 10,265 clinical specimens, 807 (7.86\%) were found to be culture positive and the occurrence of Acinetobacter was found to be 125 (15.48\%). 113 (23.01\%) of Acinetobacter species were isolated from in-patients and $12(3.78 \%)$ from out-patients (Table 2).

Table 2: Status of bacterial infections in suspected patients

\begin{tabular}{|c|c|c|c|c|}
\hline \multirow{2}{*}{ Category } & \multicolumn{2}{|c|}{ Culture } & \multirow{2}{*}{ Total N (\%) } & \multirow{2}{*}{$\begin{array}{c}\text { Acinetobacter spp. } \\
\text { N (\%) }\end{array}$} \\
\hline & Positive N (\%) & Negative N (\%) & & \\
\hline In-patients & $491(13.96)$ & $3025(86.04)$ & $3516(34.25)$ & $113(23.01)$ \\
\hline Out-patients & $316(4.68)$ & $6433(95.32)$ & $6749(65.74)$ & $12(3.78)$ \\
\hline Total & $807(7.86)$ & $9458(92.16)$ & 10265 & $125(15.48)$ \\
\hline
\end{tabular}

Amidst the Acinetobacter isolates, 65 (52\%) were was obtained from ear swab (Figure 1). obtained from neonates' blood whereas only $1(0.8 \%)$

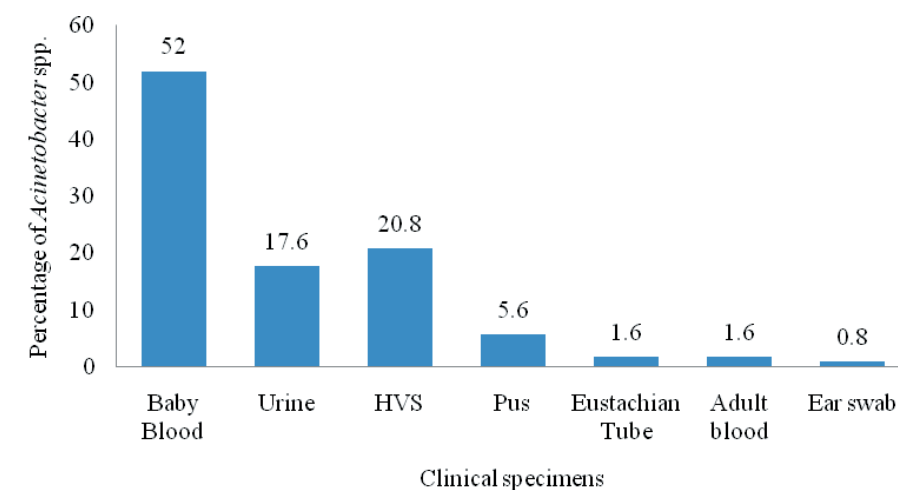

Figure 1: Distribution of Acinetobacter spp. in clinical specimens 
Out of 125 Acinetobacter spp., the most predominant species was Acinetobacter calcoaceticus-baumannii (Acb

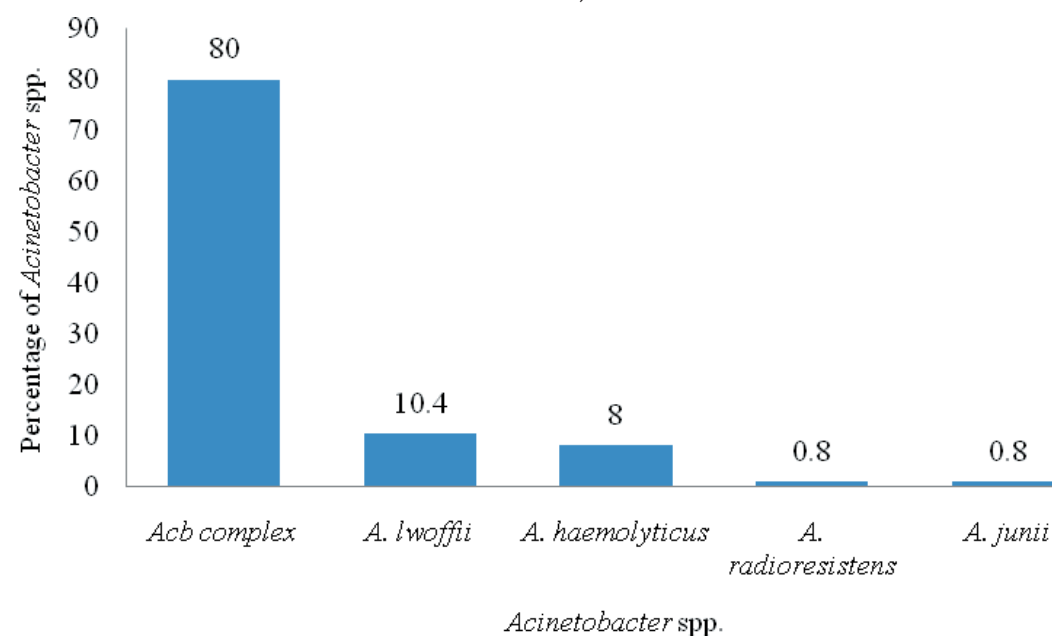

Figure 2: Distribution of various species of Acinetobacter

Amongst total 125 Acinetobacter spp., 67 (53.6\%) of the isolates were resistant towards Cefotaxime and 55 sensitive towards Colistin followed by Tetracycline (85.6\%) (Table 3).

(44\%) towards Piperacillin while all the isolates were

Table 3: Antibiotic susceptibility profile of Acinetobacter spp. $(\mathbf{n}=125)$.

\begin{tabular}{|c|c|c|c|c|}
\hline \multirow{2}{*}{ Antibiotics } & \multicolumn{2}{|c|}{ Sensitive } & \multicolumn{2}{|c|}{ Resistant } \\
\hline & No. & $\%$ & No. & $\%$ \\
\hline Amikacin & 93 & 74.4 & 32 & 25.6 \\
\hline Cefotaxime & 58 & 46.4 & 67 & 53.6 \\
\hline Ciprofloxacin & 104 & 83.2 & 21 & 16.8 \\
\hline Colistin & 125 & 100 & 0 & 0 \\
\hline Gentamicin & 92 & 73.6 & 33 & 26.4 \\
\hline Meropenem & 90 & 72 & 35 & 28 \\
\hline Piperacillin & 70 & 56 & 55 & 44 \\
\hline Piperacillin-Tazobactam & 100 & 80 & 25 & 20 \\
\hline Tetracycline & 107 & 85.6 & 18 & 14.4 \\
\hline Trimethoprim-Sulfamethoxazole & 79 & 63.2 & 46 & 36.8 \\
\hline
\end{tabular}

Of the total Acinetobacter spp. 56 (44.8\%) were MDR, $32(57.14 \%)$ were ESBL producer, 18 (32.14\%) were MBL producer and 2 (3.57\%) were AmpC $\beta$-lactamase producer. The ESBL production and MBL production in
MDR isolates were found to be statistically significant while the AmpC $\beta$-lactamase production in MDR isolates was found to be statistically insignificant (Table 4).

Table 4: Profile of $\beta$-lactamase producing Acinetobacter species

\begin{tabular}{lcccccc}
\hline \multirow{2}{*}{ Tests } & \multicolumn{2}{c}{ ESBL } & \multicolumn{2}{c}{ MBL } & \multicolumn{2}{c}{ AmpC B-lactamase } \\
\cline { 2 - 7 } & Positive & Negative & Positive & Negative & Positive & Negative \\
N (\%) & N (\%) & N (\%) & N (\%) & (\%) \\
\hline MDR & $32(57.14)$ & $24(42.86)$ & $18(32.14)$ & $38(67.86)$ & $2(3.57)$ & $54(96.43)$ \\
Non MDR & $22(31.88)$ & $47(68.12)$ & $1(1.45)$ & $68(98.55)$ & $0(0)$ & $69(100)$ \\
Total & 54 & 71 & 19 & 106 & 2 & 123 \\
\hline p-value & 0.005 & & 0.001 & & 0.114 & \\
\hline
\end{tabular}

Among 125 Acinetobacter spp. 57.14\% of the isolates were MDR and ESBL producer, 32.14\% were MDR and MBL producer, $3.57 \%$ of the isolates were MDR and AmpC producer, $17.85 \%$ of the isolates were MDR and both ESBL as well as MBL producer while $1.78 \%$ of the isolates produced all the three beta lactamase enzymes along with being MDR isolate (Table 5). 
Table 5: Relationship between MDR, ESBL, MBL and AmpC $\beta$-lactamase production in Acinetobacter spp.

\begin{tabular}{|c|c|c|}
\hline \multirow{2}{*}{ Characteristics } & \multicolumn{2}{|c|}{ Acinetobacter spp. } \\
\hline & No. & $\%$ \\
\hline$M D R+E S B L$ & 32 & 57.14 \\
\hline$M D R+M B L$ & 18 & 32.14 \\
\hline$M D R+A m p C$ & 2 & 3.57 \\
\hline$M D R+E S B L+M B L$ & 10 & 17.85 \\
\hline$M D R+E S B L+A m p C$ & 1 & 1.78 \\
\hline$M D R+M B L+A m p C$ & 1 & 1.78 \\
\hline$M D R+E S B L+M B L+A m p C$ & 1 & 1.78 \\
\hline
\end{tabular}

\section{DISCUSSION}

Acinetobacter species are ubiquitous organisms and prevail in natural environments (Kolk et al. 2019). They also represent the normal flora in humans (Almasaudi 2016). Transmission of isolate is usually through the hands of staff, contaminated equipment or overall hospital environment. Moreover, the virulence factors of Acinetobacter spp. are porins, surface structures such as capsular polysaccaharide and lipopolysaccaharide (LPS), phospholipases, iron acquisition systems, outer membrane vesicles, protein secretion systems, regulatory proteins, biofilm associated proteins, different types of binding proteins. They are also well suited for genetic exchange and have the remarkable capacity for acquisition of foreign genetic material, which helps in obtaining resistance to the antibiotics (Kolk et al. 2019).

The incidence of Acinetobacter spp. from in-patients was found to be $90.4 \%$, which is in accordance with previous studies carried out by Gupta et al. (2015) and Joshi et al. (2017). The incidence of Acinetobacter infection was highest in in-patients and highest number of bacteria was isolated from neonates' blood as also stated by Gupta et al. (2015). It is because Acinetobacter spp. is low virulence organism responsible for opportunistic infections in immuno-compromised patients, which increases the incidence of nosocomial infections. One of the reasons for the increased nosocomial infections by Acinetobacter spp. might be their endurance in dry conditions for long period of time and survival in a hospital environment and on the surface of healthcare worker hands (Park et al. 2017). The immune system of neonates is immature when they are born and it takes time to fully develop this immunity and thus they are easily attacked by various bacterial pathogens (Park et al. 2017).

The predominantly isolated species was Acinetobacter calcoaceticus baumanii (Acb complex) as also reported by Raina et al. (2015) and Gupta et al. (2015). Almost half of the isolates were multi-drug resistant which is consistent with previous reports by Pathak et al. (2017) and Shrestha et al. (2015). The development of resistance in Acinetobacter spp. may be due to the presence of wide array $\beta$-lactamases that hydrolyze and confer resistance to penicillins, cephalosporins and carbapenems, presence of efflux pumps and loss of porin proteins. Also the inappropriate use of antibiotics and lack of hygiene practices are also the factors that help in the spread of antibiotic resistant bacteria (Awad et al. 2016; Khanal et al. 2013).

Of the total Acinetobacter spp., 54 (43.2\%) were ESBL producer, $19(15.2 \%)$ were MBL producer and 2 (1.6\%) were AmpC $\beta$-lactamase producer while 1.78\% of the isolates (Acinetobacter calcoaceticus baumanii) produced all the three beta lactamase enzymes along with being MDR isolate. ESBL production and MBL production in MDR Acinetobacter spp. was found to be statistically significant while AmpC production in MDR Acinetobacter spp. was found to be statistically insignificant.

ESBL production might be due to the presence of ESBL producing genes like $b l a_{O X A-23}$ and antibiotic genes that can be transferred to other bacteria horizontally through conjugation and due to excessive use of broad spectrum antibiotics (Joshi et al. 2017; Shrestha et al. 2017). The acquisition of MBL-encoding genes such as vim1, vim2, imp1 and imp2 is one of the ways to acquire resistance to carbapenems like imipenem, meropenem and ertapenem (Davoodi et al. 2015). Phenotypic detection of AmpC $\beta$-lactamase enzyme is generally considered inappropriate because there are no standardized screening methods and also there are no CLSI recommended guidelines (Saad et al. 2016). Molecular methods are the most reliable and appropriate methods for the detection of AmpC $\beta$-lactamase enzyme (Delgado et al. 2016). 
Acinetobacter spp. are becoming the troublesome pathogen with multiple antibiotic resistance mechanisms, especially in hospital settings. Thus, infection prevention and control measures are required to minimize or prevent the transmission of infections and antibiotic stewardship programs can be implemented effectively in hospitals for optimizing the treatment of infections and reducing adverse events associated with antibiotic use.

\section{CONCLUSION}

Acinetobacter calcoaceticus-baumannii was the most common bacterial isolate which was mostly recovered from neonates' blood. All isolates were sensitive to Colistin while more than half of the isolates were resistant towards Cefotaxime and Piperacillin. Significant proportions of ESBL, MBL and AmpC beta lactamase producers were MDR. This suggests for regular monitoring of these resistant pathogens for their control.

\section{ACKNOWELDGEMENTS}

The authors acknowledge Paropakar Maternity and Women's Hospital, Kathmandu, Nepal for laboratory facilities and other support.

\section{CONFLICT OF INTEREST}

The authors declare no conflict of interest.

\section{REFERENCES}

Almasaudi SB (2016). Acinetobacter spp. as nosocomial pathogens: Epidemiology and resistance features. Saudi J Biol Sci 25(3): 586-596.

Anwar M, Ejaz H, Zafar A and Hamid H (2016). Phenotypic Detection of Metallo-Beta-Lactamases in Carbapenem Resistant Acinetobacter baumannii Isolated from Pediatric Patients in Pakistan. J Pathog 6: 7-12.

Awad HA, Mohamed MH, Badran NF, Mohsen M and Abd-Elrhman AS (2016). Multidrug-resistant organisms in neonatal sepsis in two tertiary neonatal ICUs, Egypt. J Egypt Pub Heal Assoc 91(1): 31-38.

Bhandari P, Thapa G, Pokhrel BM, Bhatta DR and Devkota U (2015). Nosocomial isolates and their resistant pattern in ICU patients at National Institute of Neurological and Allied Sciences, Nepal. Int J Microbiol 1: 1-6.

Clinical and Laboratory Standard Institute (CLSI
2018). Performance standards for antimicrobials susceptibility testing: $24^{\text {th }}$ informational supplement (M100-S23). CLSI, Wayne PA, USA.

Davoodi S, Ali Baroumand M, Sepehriseresht S and Pourgholi L (2015). Detection of VIM- and IMP-type Metallo-Beta-Lactamase Genes in Acinetobacter baumannii Isolates from Patients in Two Hospitals in Tehran. Iran J Biotechnol 13(1): 63-67.

Delgado DY, Barrigas ZP, Astutillo SG, Jaramillo AP and Ausili A (2016). Detection and molecular characterization of $\beta$-lactamase genes in clinical isolates of Gram-negative bacteria in Southern Ecuador. Braz J Infect Dis 20(6): 627-630.

Gordon NC and Wareham DW (2009). Multidrugresistant Acinetobacter baumannii: mechanisms of virulence and resistance. Int J Antimicrob Agents 35(3): 219-226.

Gupta N, Gandhan N, Jadhav S and Mishra R (2015). Isolation and identification of Acinetobacter species with special reference to antibiotic resistance. J Nat Sci Biol Med 6(1): 159-162.

Joshi PR, Acharya M, Kakshapati T, Leungtongkam U, Thummeepak R and Sitthisak S (2017). Co-existence of $b l a_{\mathrm{OXA}-23}$ and $b l a_{\mathrm{NDM}-1}$ genes of Acinetobacter baumannii isolated from Nepal: antimicrobial resistance and clinical significance. Antimicrob Resist Infect Control 6: 21-27.

Kaye K and Pogue J (2015). Infections Caused by Resistant Gram Negative Bacteria: Epidemiology and Management. Pharmacotherapy 35(10): 949962.

Khanal S, Joshi DR, Bhatta DR, Devkota U and Pokhrel BM (2013). $\beta$-Lactamase-Producing MultidrugResistant Bacterial Pathogens from Tracheal Aspirates of Intensive Care Unit Patients at National Institute of Neurological and Allied Sciences, Nepal. ISRN Microbiol 2013: 1-5.

Kolk J, Endimiani A, Granubner C, Gerber V and Perreten V (2019). Acinetobacter in veterinary medicine, with an emphasis on Acinetobacter baumannii.J Glob Antimicrob Resist 16: 59-71.

Magiorakos AP, Srinivasan A and Carey RB (2012). Multi drug resistant, extensively drug-resistant and pandrug-resistant bacteria: an international 
expert proposal for interim standard definitions for acquired resistance. Clin Microbiol Infect 18(3): 268-281.

Park G, Kang C, Cha M, Cho S, Seok H, Lee J, Kim J, Ha Y, Chung D, Peck K, Lee N and Song J (2017). Bloodstream infections caused by Acinetobacter species with reduced susceptibility to tigecycline: clinical features and risk factors. Int J Infect Dis 62: 26-31.

Pathak P, Jaishi N, Yadav BK and Shah PK (2017). Prevalence of Extended Spectrum Beta Lactamases (ESBL) and Metallo Beta Lactamases (MBL) Mediated Resistance in Gram Negative Bacterial Pathogens. Tribhuvan University Journal of Microbiology 4: 49-54.

Perez F, Hujer AM, Hujer KM, Decker BK, Rather PN, and Bonomo RA (2007). Global challenge of multidrug-resistant Acinetobacter baumannii. Antimicrob Agents Chemother 51(10): 3471-3484.

Peymani A, Nahaei MR, Farajnia S, Hasani A, Mirsalehian A, Sohrabi N and Abbasi L (2011). High prevalence of Metallo-beta-lactamaseproducing Acinetobacter baumannii in a teaching hospital in Tabriz, Iran. Jpn J Infect Dis 64(1): 6971.

Raina D, Sharma N, Mahawal BS, Khanduri A and Pandit A (2015). Speciation and antibiotic resistance pattern of Acinetobacter species in a tertiary care hospital in Uttarakhand. Int J Medi Resear Heal Sci 5(4): 89-96.
SaadN, Munir T, Ansari M, Gilani M, Latif M and Haroon A (2016). Evaluation of phenotypic tests for detection of Amp C beta-lactamases in clinical isolates from a tertiary care hospital of Rawalpindi, Pakistan.J Pak Med Assoc 66(6): 658661.

Shrestha S, Tada T, Akiyama T, Ohara H, Shimada K, Satou K, Teruya K, Nakano K, Shiroma A, Sherchand JB, Rijal BP, Hirano T, Kirikae T and Pokhrel BM (2015). Molecular epidemiology of multidrug-resistant Acinetobacter baumannii isolates in a university hospital in Nepal reveals the emergence of a novel epidemic clonal lineage. Int J Antimicrob Agents 46(5): 526-531.

Silveira F, Nedel WL, Cassol R, Pereira PR, Deutschendorf C and Lisboa T (2019). Acinetobacter etiology respiratory tract infections associated with mechanical ventilation: what impacts on the prognosis? A retrospective cohort study. J Crit Care 49: 124-128.

Soudeiha M, Sokhn E, Daoud Z, Sarkis D (2018) Molecular epidemiology and clonality of Acinetobacter spp. in a Lebanese hospital over a period of one year. J Infect Dev Ctries 12: 17-22.

Sujatha R and Goyal R (2017). A Study of Phenotypic \& Genotypic Assays For Detection of Metallo $\beta$ - Lactamase Producing Pseudomonas aeruginosa With Special Reference to New Delhi Metallo $\beta$ Lactamase. J Den Med Sci 16(7): 90-96. 